\title{
Simultaneous determination of fluorine, chlorine and sulfur in incinerator residues by oxidative high pressure digestion and ion chromatography
}

\author{
H. Belevi* and H. Mönch
}

\author{
Swiss Federal Institute for Environmental Science and Technology (EAWAG), CH-8600 Dubendorf, Switzerland
}

\begin{abstract}
An oxidative high pressure digestion method is presented to dissolve fluorine, chlorine and sulfur components of municipal solid waste incinerator residues. It is a combination of the classical high pressure digestion technique with the combustion in a closed system. The concentration determination is carried out by ion chromatography. The results are compared with those obtained by other digestion and extraction methods combined also with ion chromatography. A CNS-analyzer is used as a further method to compare the sulfur concentrations. Based on the obtained data, the accuracy of the fluorine, chlorine and sulfur concentrations is estimated as better than $85 \%$. It is concluded, that the oxidative high pressure digestion combined with ion chromatography is an appropriate method to determine fluorine, chlorine and sulfur concentrations in incinerator residues. Its main advantage is the simultaneous analysis of these three elements. However, it is a time consuming method.
\end{abstract}

Keywords. Bottom ash - fly ash - fluorine - chlorine - sulfur.

\section{Introduction}

About $30 \%$ of the generated municipal solid waste is currently incinerated in industrialized nations and this per cent is increasing rapidly as a result of the recently implemented strategies and guidelines. These guidelines for sustainable resource management require that municipal solid waste (MSW) incinerators produce solid residues without any environmental concerns. They pose, however, a potential problem due to their high heavy metal content compared to geogenic materials. Therefore, incinerators should separate the environmentally harmful compounds from MSW and concentrate them in the air pollution control residues. Thus, bottom ash could be used as a construction material or landfilled on a long-term basis without causing environmentally damaging effects, and air pollution control residues could become attractive for resource recovery processes. However, a more efficient separation of heavy metals can only be achieved if the factors determining element transfers from MSW to incinerator products are understood.

In recent years, factors determining the element behavior in incinerators are investigated [1-5]. In addition to temperature and redox conditions, the chlorine concentration in the furnace bed have significant effect on the evaporation behavior of many elements in the furnace. Furthermore, the content of reaction partners other than oxygen and chlorine can also influence the chemical reactions. One of these elements is sulfur. It can delay evaporation of many elements. Heavy metals can form sulfates and, thus, prevent evaporation of such metals as chlorides. Consequently, studies aimed at process understanding in incinerators require precise methods for the determination of sulfur and chlorine in the incinerator products. Fluorine also undergo several chemical reactions in the furnace bed. The effect of fluorine on the behavior of other elements is however small due to its low concentration in the municipal solid waste [4].

Many different methods exist for sulfur, chlorine and fluorine determination in incineration residues [6]. For example, sulfur and chlorine can be determined directly by X-ray fluorescence spectrometry. Since chlorine and sulfur are light elements, this method requires, however, very fine powdered samples to obtain pellets with homogenous surfaces. Chlorine and fluorine can be determined by ion chromatography or potentiometry using ion selective electrodes after a digestion according to Wurzschmitt [7] or in hot sodium hydroxide. Sulfur can also be directly analyzed with CNS-Analyzers. The method is based on the combustion of the sample in a flow of oxygen enriched helium using catalysts. The gas is routed through a gas chromatograph and sulfur is detected as sulfur dioxide by thermal conductivity or infrared detection systems. This method provides precise results for organic matrixes. However, some thermally stable inorganic substances cannot be always volatilized in the furnace [8]. Incomplete volatilization causes a low analytical accuracy, examined by means of comparative analysis of the reference materials [6].

This paper presents a digestion method for incinerator residues which allows a complete dissolution of sulfur, chlorine and fluorine. It is a combination of the classical high 
pressure digestion technique with the combustion in a closed system. A comparison of this method with diluted nitric acid extraction and Wurzschmitt digestion, as well as with sulfur determination with CNS-analyzer is also presented.

\section{Experimental}

\section{Sampling and sample preparation}

Bottom ash, electrostatic precipitator dust (ESPD) and air pollution control (APC) residue samples were taken in the incinerator in Oftringen in Switzerland. It is a grate furnace construction type with a combustion capacity of 8 tons per hour. Bottom ash is quenched with water after leaving the furnace.

The entire bottom ash produced during one hour (about 2 tons) was collected after the quench tank and unloaded onto a screen. The residues over $100 \mathrm{~mm}$ were not taken. The ash passing the screen was mixed thoroughly with shovels and a 2-4 kg sample was taken for subsequent analyses.

The electrostatic precipitator dust samples were collected directly after the electrostatic precipitator out of the chain conveyor before the storage tank. Sampling is accomplished by preparing a composite of five sub-samples of about $0.5 \mathrm{~kg}$. They were mixed thoroughly with a shovel.

The APC residues were collected after the stabilization with cement out of the containers which are used for the transport to the landfill. They contain electrostatic precipitator dust mixed with the scrubber sludge. They were washed with water prior to stabilization to remove the most of chlorides. Sampling is accomplished by preparing a composite of five sub-samples of about $1 \mathrm{~kg}$. They were taken from different places of the containers, mixed thoroughly with a shovel and a composite sample of about $2 \mathrm{~kg}$ was taken for the subsequent analyses.

All the solid samples were dried at $105{ }^{\circ} \mathrm{C}$ for $24 \mathrm{~h}$. Bottom ash samples were ground for four hours in a steel ball mill and sieved through a $0.5 \mathrm{~mm}$ screen. The amount of oversize material totalled between $4 \mathrm{wt} \%$ and $11 \mathrm{wt} \%$. The material passing the screen was used as fine ground laboratory samples for element analyses. ESPD and APC residue samples were ground in a hammer mill. All the resulting powdered dust completely passed the $0.5 \mathrm{~mm}$ screen and were used for element analysis.

\section{Reagents}

All reagents used were analytical grade.

\section{Digestion and extraction methods}

\section{Oxidative high pressure digestion}

The oxidative high pressure digestion was carried out in the special bomb AOD1 of the company IKA Werke GMBH, Germany. The system consists of a digestion vessel, oxygen filling station and an external ignition unit. Figure 1 shows the scheme of the digestion bomb. It is made of high-grade alloys of stainless steel compounds. The inner surface is coated with auto-regenerating catalysts. The sample is oxidized by combustion in the bomb containing oxygen under 34 bar pressure. The liberated gases containing sulfur and halogen compounds are absorbed in a solution consisting of sodium hydroxide and hydrogen peroxide.

The inner surface of the digestion vessel is wetted by $10 \mathrm{ml} 0.5 \mathrm{M}$ sodium hydroxide solution. About $0.1 \mathrm{ml} 30 \%$ hydrogen peroxide is added. A capsule of acetobutyrate with weighed amount of sample $(0.1-0.2 \mathrm{mg})$ is placed in the quartz container. About $0.8-1.5 \mathrm{ml}$ paraffin oil and $0.2 \mathrm{~g}$ titan is then given into the capsule. The firing wire is attached to the electrodes so that it is just above and not touching the sample. A cotton thread is looped around the wire so that the ends will extend into the cup and dips into the sample. The bomb is then assembled and tightened securely. Oxygen is admitted slowly until a pressure of 34 bar. The electrical circuit is closed to ignite the sample. The bomb is immersed in a ice bath. It is removed from the bath after about 15 minutes and shaken heavily for about 3 minutes. The pressure is released at a slow, uniform rate. The bomb is opened and the contents are examined. If traces of sooty deposits are found, the determination is discarded and the bomb is cleaned thoroughly before using it again. The upper part and the interior of the bomb is rinsed with a $0.25 \mathrm{M}$ sodium hydroxide into the digestion solution. The digestion solution is diluted to $250 \mathrm{ml}$ with deionized water for the subsequent analyses by ion chromatography.

\section{Wurzschmitt digestion}

About $100 \mathrm{mg}$ of exactly weighed sample is mixed with 3-5 g sodium peroxide and 5-8 drops glycerin. The mixture is heated up with a flame in a closed combustion device according to Wurzschmitt [8] for about $1 \mathrm{~min}$. The reaction

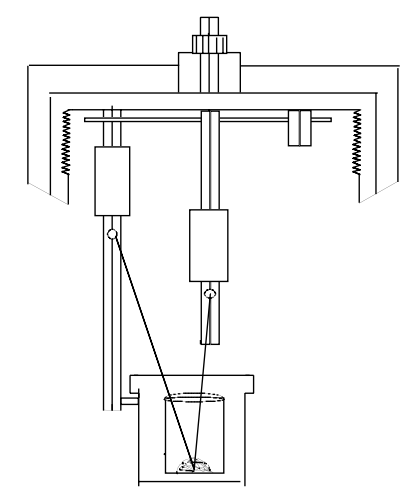

Upper part with electrodes, firing wire and sample container made of quartz

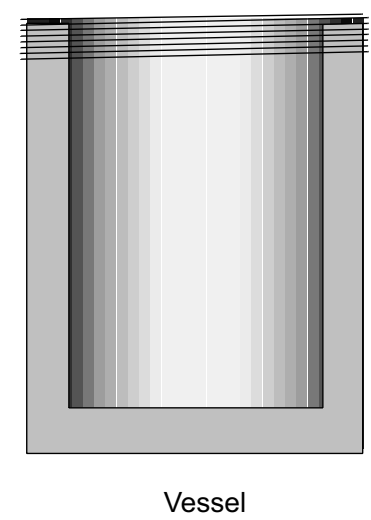

Figure 1. Scheme of the of the digestion bomb. 


\section{Original articles}

products are absorbed in deionized water. The solution was subjected to the analysis by ion chromatography.

\section{Diluted nitric acid extraction}

About $2 \mathrm{~g}$ of exactly weighed sample is extracted with $100 \mathrm{ml} 0.1 \mathrm{M} \mathrm{HNO}_{3}$ solution at room temperature on a rotary shaker at $125 \mathrm{rpm}$ for $15 \mathrm{~h}$. The solution is filtered over a $0.45 \mu$ membrane filter and diluted to $100 \mathrm{ml}$ with deionized water. The solution was subjected to the analysis by ion chromatography.

\section{Instruments and operating conditions}

\section{CNS-Analyzer}

Sulfur is determined simultaneously with the CNS-Analyzer of Carlo Erba CNS 1500. The method is based on flashcombustion of the sample in a flow of temporarily oxygenenriched helium, catalytic oxidation and reduction of the combustion gases within the same reactor, gas chromatographic separation and thermal-conductivity detection of the products. Copper and tungsten oxide are used as catalysts. The combustion gases are carried via a stream of helium gas to a detector. About $5-10 \mathrm{mg}$ of exactly weighed sample is mixed with $3 \mathrm{mg}$ vanadium pentoxide and placed in a tin capsule. The capsule is directly driven into the furnace where combustion takes place.

\section{Ion chromatograph}

An ion chromatograph (SYKAM) with an anion-exchange column (A04), a suppressor (S2210) and a conductivity detector was used. The mobile phase consisted of $12 \mathrm{mM}$ sodium carbonate and $15 \mathrm{mM}$ sodium bicarbonate. The flow rate was $2 \mathrm{ml} / \mathrm{min}$ and the column temperature $50{ }^{\circ} \mathrm{C}$.

\section{Results and discussion}

Unfortunately, not a high number of municipal solid waste incinerator residue standards exist. Three certified reference materials are chosen for the comparative analyses. BCR 176 is a fly ash certified by the Community Bureau of Reference, Commission of the European Communities. BCS 382 is a blast furnace slag certified by the British Bureau of Analysed Samples. Cement XO208 is a Portland cement sample obtained from the company Kupper+Co, Bonaduz, Switzerland. BCR 176 represents the ESPD and APCresidues. BCS 382 is chosen for bottom ash, even though the composition of incinerator bottom ash and that of blast furnace slag are not equal. Cement standard is chosen to control if the oxidative high pressure digestion method can dissolve the cement minerals containing fluorine and sulfur.

Table I shows measured concentrations by the oxidative high pressure digestion and the subsequent ion chromatography, as well as a comparison with the certified values. The fluorine concentration is not certified in BCR 176. The chlorine concentration is an indicative value determined by the instrumental neutron activation analysis. The measured value
Table I. Recovery studies of fluorine, chlorine and sulfur in certified reference materials.

\begin{tabular}{llccc}
\hline Sample & Values & $F$ & $C l$ & $S$ \\
\hline BCR 176 & Certified $[\mathrm{g} / \mathrm{kg}]$ & n.d. & $41^{*}$ & 34.9 \\
& Found $[\mathrm{g} / \mathrm{kg}]$ & 2.72 & 58.5 & 35.4 \\
& $s[\mathrm{~g} / \mathrm{kg}]$ & 0.10 & 1.7 & 0.1 \\
& $n$ & 3 & 3 & 3 \\
BCS 382 & Certified $[\mathrm{g} / \mathrm{kg}]$ & 1 & $\mathrm{n} . \mathrm{d}$. & 3.7 \\
& Measured $[\mathrm{g} / \mathrm{kg}]$ & 0.79 & 0.48 & 3.42 \\
& $s$ [g/kg] & 0.07 & 0.02 & 0.11 \\
& $n$ & 3 & 3 & 3 \\
Cement XO208 & Certified $[\mathrm{g} / \mathrm{kg}]$ & 1 & 0.3 & 10.2 \\
& Measured $[\mathrm{g} / \mathrm{kg}]$ & 0.90 & $<0.3$ & 9.50 \\
& $s$ [g/kg] & 0.04 & n.d. & 0.15 \\
& $n$ & 3 & 3 & 3 \\
\hline
\end{tabular}

nd: not determined

$s$ : Standard deviation

$n$ : Number of determinations

*: indicative value

is about $40 \%$ higher than the indicative value. The measured sulfur concentration in BCR 176 agrees with the certified value. Chlorine is not certified in BCS 182. The measured fluorine and sulfur concentrations are about $20 \%$ and $8 \%$ lower than the certified values, respectively. The chlorine concentration in Cement XO208 was lower than the determination limit of $0.3 \mathrm{~g} / \mathrm{kg}$. The measured fluorine concentration is about $10 \%$ lower and the measured sulfur concentration is about $7 \%$ lower than the corresponding certified values.

Table II contains the fluorine concentration in bottom ash and in ESPD determined by different digestion and extraction methods combined with the subsequent ion chromatography. The oxidative high pressure digestion provides the highest results in bottom ash and in ESPD. The dissolution of fluorine, present in bottom ash, is not complete by the extraction with diluted nitric acid. The fluorine concentrations determined by this procedure are about $50 \%$ lower than the oxidative high pressure digestion. Wurzschmitt digestion provides, however, almost the same fluorine concentrations as the oxidative high pressure digestion. The fluorine concentrations in ESPD determined by the extraction with diluted nitric acid and by the Wurzschmitt digestion are about $10 \%$ lower than those determined by the oxidative high pressure digestion.

The chlorine concentrations in bottom ash and in ESPD determined by different procedures are given in table III. Extraction with diluted nitric acid provides about $14 \%$ lower and the Wurzschmitt digestion about $6 \%$ lower chlorine concentrations than the oxidative high pressure digestion. The concentrations determined by the diluted nitric acid extractions and Wurzschmitt digestion are, however, up to $15 \%$ higher than those determined by the oxidative high pressure digestion. 
Table II. Fluorine concentrations in bottom ash and in ESPD determined by different extraction techniques and the subsequent ion chromatography.

\begin{tabular}{|c|c|c|c|c|}
\hline Sample & Values & $\begin{array}{c}\text { Oxidative high } \\
\text { pressure digestion }\end{array}$ & $\begin{array}{c}\text { Extraction } \\
\text { with } 0.1 \mathrm{M} \mathrm{HNO}_{3}\end{array}$ & $\begin{array}{l}\text { Wurzschmitt } \\
\text { digestion }\end{array}$ \\
\hline Bottom ash & $\begin{array}{l}\text { Average }[\mathrm{g} / \mathrm{kg}] \\
s[\mathrm{~g} / \mathrm{kg}] \\
n \\
\text { Ratio to oxidative high pressure digestion [\%] }\end{array}$ & $\begin{array}{c}0.26 \\
0.04 \\
2 \\
100\end{array}$ & $\begin{array}{l}0.14 \\
0.03 \\
5 \\
54\end{array}$ & $\begin{array}{c}0.25 \\
0.01 \\
2 \\
96\end{array}$ \\
\hline ESPD & $\begin{array}{l}\text { Average }[\mathrm{g} / \mathrm{kg}] \\
s[\mathrm{~g} / \mathrm{kg}] \\
n \\
\text { Ratio to oxidative high pressure digestion [\%] }\end{array}$ & $\begin{array}{c}2.90 \\
0.02 \\
2 \\
100\end{array}$ & $\begin{array}{c}2.53 \\
0.10 \\
5 \\
88\end{array}$ & $\begin{array}{c}2.58 \\
0.49 \\
2 \\
89\end{array}$ \\
\hline
\end{tabular}

$s:$ Standard deviation

$n$ : Number of determinations

Table III. Chlorine concentrations in bottom ash and in ESPD determined by different extraction techniques and the subsequent ion chromatography.

\begin{tabular}{|c|c|c|c|c|}
\hline Sample & Values & $\begin{array}{c}\text { Oxidative high } \\
\text { pressure digestion }\end{array}$ & $\begin{array}{c}\text { Extraction } \\
\text { with } 0.1 \mathrm{M} \mathrm{HNO}_{3}\end{array}$ & $\begin{array}{l}\text { Wurzschmitt } \\
\text { digestion }\end{array}$ \\
\hline Bottom ash & $\begin{array}{l}\text { Average }[\mathrm{g} / \mathrm{kg}] \\
s[\mathrm{~g} / \mathrm{kg}] \\
n \\
\text { Ratio to oxidative high pressure digestion [\%] }\end{array}$ & $\begin{array}{l}4.10 \\
0.08 \\
2 \\
100\end{array}$ & $\begin{array}{c}3.54 \\
0.10 \\
5 \\
86\end{array}$ & $\begin{array}{l}3.85 \\
0.26 \\
2 \\
94\end{array}$ \\
\hline ESPD & $\begin{array}{l}\text { Average }[\mathrm{g} / \mathrm{kg}] \\
s[\mathrm{~g} / \mathrm{kg}] \\
n \\
\text { Ratio to oxidative high pressure digestion [\%] }\end{array}$ & $\begin{array}{c}73.0 \\
2.2 \\
2 \\
100\end{array}$ & $\begin{array}{c}84.1 \\
1.5 \\
5 \\
115\end{array}$ & $\begin{array}{c}77.6 \\
4.5 \\
2 \\
106\end{array}$ \\
\hline
\end{tabular}

$s:$ Standard deviation

$n$ : Number of determinations

Table IV contains the sulfur concentrations in bottom ash and in ESPD determined by different extraction techniques and the subsequent ion chromatography, as well as with the CNS-Analyzer. The concentrations determined by the oxidative high pressure digestion combined with ion chromatography and with the CNS-analyzer are almost equal. Extraction with diluted nitric acid provides lower sulfur concentrations. About $16 \%$ higher concentrations were measured in bottom ash by Wurzschmitt digestion and the subsequent ion chromatography. The concentrations in ESPD are however about $8 \%$ lower than those determined by the oxidative high pressure digestion.

These results indicate that the differences between the concentrations determined by the oxidative high pressure digestion combined with the subsequent ion chromatography and the other methods are lower than $15 \%$. The differences to the certified values are even lower than $10 \%$ (Tab. I). The fluorine concentration in BCS 382 is an exception, which is about $20 \%$ lower than the certified value. Based on these data, the analytical accuracy of the oxidative high pressure digestion method, operationally defined by means of comparative analyses of the reference materials and by means of comparative determination by different methods, is assessed as better than $85 \%$ for all three elements.

Table V shows the fluorine, chlorine and sulfur concentrations in bottom ash determined in the incinerator of Oftringen in 1998. These measurements were carried out to establish a material bookkeeping method in the plant [9]. The fluorine and chlorine concentrations were determined only by the oxidative high pressure digestion and the subsequent ion chromatography. Sulfur concentrations were also determined with the CNS-analyzer. Fluorine concentrations vary between $0.20 \mathrm{~g} / \mathrm{kg}$ and $0.45 \mathrm{~g} / \mathrm{kg}$, chlorine concentrations between $2.1 \mathrm{~g} / \mathrm{kg}$ and $3.9 \mathrm{~g} / \mathrm{kg}$, and sulfur concentrations between $2.5 \mathrm{~g} / \mathrm{kg}$ and $8.7 \mathrm{~g} / \mathrm{kg}$. CNS-analyzer provides, on average, about $11 \%$ higher sulfur concentrations. However the minimal ratio is about $73 \%$ and the maximal ratio about $136 \%$.

Concentrations in APC residues are given in table VI. Fluorine concentrations vary between $1.9 \mathrm{~g} / \mathrm{kg}$ and $4.1 \mathrm{~g} / \mathrm{kg}$, chlorine concentrations between $3.2 \mathrm{~g} / \mathrm{kg}$ and $7.9 \mathrm{~g} / \mathrm{kg}$, and 


\section{Original articles}

Table IV. Sulfur concentrations in bottom ash and in ESPD determined by different extraction techniques and the subsequent ion chromatography, as well as with the CNS-analyzer.

\begin{tabular}{|c|c|c|c|c|c|}
\hline Sample & Values & $\begin{array}{c}\text { Oxidative high } \\
\text { pressure digestion }\end{array}$ & $\begin{array}{c}\text { Extraction } \\
\text { with } 0.1 \mathrm{M} \mathrm{HNO}_{3}\end{array}$ & $\begin{array}{l}\text { Wurzschmitt } \\
\text { digestion }\end{array}$ & $C N S$ \\
\hline \multirow[t]{4}{*}{ Bottom ash } & Average $[\mathrm{g} / \mathrm{kg}]$ & 3.13 & 2.77 & 3.64 & 3.04 \\
\hline & $s[\mathrm{~g} / \mathrm{kg}]$ & 0.06 & 0.20 & 0.04 & 0.10 \\
\hline & $n$ & 2 & 5 & 2 & 3 \\
\hline & Ratio to oxidative high pressure digestion [\%] & 100 & 89 & 116 & 97 \\
\hline \multirow[t]{4}{*}{ ESPD } & Average $[\mathrm{g} / \mathrm{kg}]$ & 73.5 & 57.2 & 67.7 & 73.3 \\
\hline & $s[\mathrm{~g} / \mathrm{kg}]$ & 0.9 & 12.2 & 3.6 & 0.7 \\
\hline & $n$ & 2 & 5 & 2 & 5 \\
\hline & Ratio to oxidative high pressure digestion [\%] & 100 & 78 & 92 & 100 \\
\hline
\end{tabular}

$s:$ Standard deviation

$n$ : Number of determinations

Table V. Fluorine, chlorine and sulfur concentrations in bottom ash determined in the incinerator of Oftringen in 1998.

\begin{tabular}{|c|c|c|c|c|c|c|c|c|c|}
\hline \multirow[t]{3}{*}{$\begin{array}{l}\text { Week } \\
\text { of } \\
\text { year }\end{array}$} & \multicolumn{6}{|c|}{$\begin{array}{l}\text { Concentration determined by the oxidative high pressure } \\
\text { digestion and the subsequent ion chromatography }\end{array}$} & \multirow{2}{*}{\multicolumn{2}{|c|}{$\begin{array}{c}\text { Concentration } \\
\text { determined with } \\
\text { CNS-analyzer } \\
\mathrm{S} \\
{[\mathrm{g} / \mathrm{kg}]}\end{array}$}} & \multirow{3}{*}{$\begin{array}{c}\text { Concentration } \\
\text { ratio CNS to } \\
\text { the digestion } \\
\text { method } \\
{[\%]}\end{array}$} \\
\hline & \multirow{2}{*}{\multicolumn{2}{|c|}{$\begin{array}{c}\mathrm{F} \\
{[\mathrm{g} / \mathrm{kg}]}\end{array}$}} & \multicolumn{2}{|c|}{$\begin{array}{c}\mathrm{Cl} \\
{[\mathrm{g} / \mathrm{kg}]}\end{array}$} & \multicolumn{2}{|c|}{$\begin{array}{c}\mathrm{S} \\
{[\mathrm{g} / \mathrm{kg}]}\end{array}$} & & & \\
\hline & & & average & $\mathrm{s}$ & average & $\mathrm{s}$ & average & $\mathrm{s}$ & \\
\hline 5 & 0.43 & 0.035 & 3.5 & 0.40 & 4.5 & 0.29 & 4.4 & 0.21 & 98 \\
\hline 8 & 0.36 & 0.085 & 2.8 & 0.05 & 3.4 & 0.01 & 4.6 & 0.17 & 136 \\
\hline 10 & 0.45 & 0.028 & 2.1 & 0.18 & 8.2 & 0.09 & 8.7 & 0.41 & 106 \\
\hline 13 & 0.40 & 0.035 & 2.9 & 0.18 & 3.0 & 0.01 & 4.1 & & 135 \\
\hline 17 & 0.31 & & 3.5 & & 4.5 & & 3.3 & & 73 \\
\hline 19 & 0.37 & 0.021 & 3.7 & 0.15 & 4.3 & 0.11 & 3.3 & 0.18 & 76 \\
\hline 22 & 0.40 & 0.042 & 2.7 & 0.11 & 3.2 & 0.24 & 4.3 & 0.33 & 133 \\
\hline 29 & 0.33 & & 2.5 & & 2.4 & & 2.5 & & 106 \\
\hline 35 & 0.31 & 0.014 & 3.8 & 0.52 & 3.2 & 0.07 & 4.0 & 0.12 & 127 \\
\hline 40 & 0.37 & & 2.4 & & 4.1 & & 4.6 & & 114 \\
\hline 42 & 0.30 & & 2.9 & & 4.6 & & 6.1 & & 133 \\
\hline 44 & 0.20 & & 2.4 & & 4.6 & & 4.6 & & 99 \\
\hline 45 & 0.38 & & 3.0 & & 6.1 & & 6.5 & 0.23 & 106 \\
\hline average & 0.35 & & 2.9 & & 4.3 & & 4.7 & & 111 \\
\hline$s$ & 0.06 & & 0.5 & & 1.5 & & 1.6 & & 21 \\
\hline Min & 0.20 & & 2.1 & & 2.4 & & 2.5 & & 73 \\
\hline Max & 0.45 & & 3.8 & & 8.2 & & 8.7 & & 136 \\
\hline
\end{tabular}

$s$ : standard deviation

sulfur concentrations between $21.3 \mathrm{~g} / \mathrm{kg}$ and $74.6 \mathrm{~g} / \mathrm{kg}$. The annual mean sulfur concentrations determined by the digestion method and with the CNS-analyzer are not significantly different from each other. The agreement is better for APC residues than for bottom ash. The lower agreement in bottom ash may be attributed to the sulfur speciation in bottom ash. As these determinations can be rather regarded as a kind of routine analysis than recovery determinations, it is likely that the decomposition of some bottom ash samples were not complete. While sulfur occurs to a high extent as water soluble sulfates in APC residues, a significant part of sulfur can occur as thermally stable compounds in bottom ash, which makes the decomposition more difficult by both methods. This is an important disadvantage of both methods, especially in routine analysis.

The analytical precision is estimated by repeating analytical determinations. Additional digestions were carried out for 7 bottom ash and 5 APC residue samples. The standard 
Table VI. Fluorine, chlorine and sulfur concentrations in APC-residues determined in the incinerator of Oftringen in 1998.

\begin{tabular}{|c|c|c|c|c|c|c|c|c|c|}
\hline \multirow[t]{3}{*}{$\begin{array}{l}\text { Week } \\
\text { of } \\
\text { year }\end{array}$} & \multicolumn{6}{|c|}{$\begin{array}{l}\text { Concentration determined by the oxidative high pressure } \\
\text { digestion and the subsequent ion chromatography }\end{array}$} & \multirow{2}{*}{\multicolumn{2}{|c|}{$\begin{array}{c}\text { Concentration } \\
\text { determined with } \\
\text { CNS-analyzer } \\
\mathrm{S} \\
{[\mathrm{g} / \mathrm{kg}]}\end{array}$}} & \multirow{3}{*}{$\begin{array}{c}\text { Concentration } \\
\text { ratio CNS to } \\
\text { the digestion } \\
\text { method } \\
{[\%]}\end{array}$} \\
\hline & \multicolumn{2}{|c|}{$\begin{array}{c}\mathrm{F} \\
{[\mathrm{g} / \mathrm{kg}]}\end{array}$} & \multicolumn{2}{|c|}{$\begin{array}{c}\mathrm{Cl} \\
{[\mathrm{g} / \mathrm{kg}]}\end{array}$} & \multicolumn{2}{|c|}{$\begin{array}{c}\mathrm{S} \\
{[\mathrm{g} / \mathrm{kg}]}\end{array}$} & & & \\
\hline & average & $s$ & average & $s$ & average & $s$ & average & $s$ & \\
\hline 5 & 4.1 & 0.91 & 5.7 & 0.45 & 56.0 & 0.2 & 58.2 & 1.4 & 104 \\
\hline 6 & 2.4 & 0.06 & 4.2 & 0.33 & 56.2 & 8.6 & 54.2 & 1.7 & 97 \\
\hline 11 & 2.2 & & 4.7 & & 53.9 & & 56.3 & 1.1 & 104 \\
\hline 13 & 2.0 & & 3.2 & & 47.9 & & 52.2 & 3.2 & 109 \\
\hline 20 & 3.2 & 0.36 & 5.1 & 0.10 & 61.2 & 0.8 & 63.5 & 1.9 & 104 \\
\hline 27 & 1.9 & 0.25 & 7.9 & 0.07 & 21.3 & 0.1 & 21.8 & 1.0 & 102 \\
\hline 32 & 3.3 & & 4.4 & & 72.0 & & 79.1 & 3.0 & 110 \\
\hline 38 & 1.9 & & 4.0 & & 46.1 & & 52.8 & 1.0 & 115 \\
\hline 42 & 1.9 & 0.20 & 7.5 & 0.44 & 59.8 & 0.4 & 60.3 & 0.6 & 101 \\
\hline 46 & 2.5 & & 4.8 & & 74.6 & & 67.2 & 1.1 & 90 \\
\hline average & 2.5 & & 5.2 & & 54.9 & & 56.6 & & 104 \\
\hline$s$ & 0.8 & & 1.5 & & 14.9 & & 14.7 & & 7 \\
\hline Min & 1.9 & & 3.2 & & 21.3 & & 21.8 & & 90 \\
\hline Max & 4.1 & & 7.9 & & 74.6 & & 79.1 & & 115 \\
\hline
\end{tabular}

s: standard deviation

deviations based on duplicate determinations are given in table $\mathrm{V}$ and VI. Based on these data, the mean precision $\sigma$ is estimated on the basis of the average standard deviation and the student's distribution. It indicates the reproducibility of the results and is here operationally defined by equation 1. Precision is improved as $\sigma$ decreases.

$$
\sigma=\mathrm{t}_{\mathrm{p}, \mathrm{n}} * \sqrt{\frac{\sum \mathrm{s}^{2}}{n}}
$$

where

$\sigma$ corresponds to the precision of each determination;

$t_{p, n}$ corresponds to the critical value of the student's distribution for $p$ confidence level and $n$ degrees of freedom;

$\mathrm{s}$ corresponds to the standard deviation;

$n$ corresponds to the number of the concentration determinations with repetitions ( 7 for bottom ash and 5 for APC-residues).

The calculated precision $\sigma$ is given in table VII. The fluorine determination shows the lowest precision ( $\sigma$ amounts to $27 \%$ and $35 \%$, respectively). The precision of the chlorine and sulfur determination is better than $20 \%$.

\section{Conclusion}

The described oxidative high pressure digestion combined with ion chromatography is an appropriate method to determine fluorine, chlorine and sulfur concentrations in incinerator residues. The main advantage of the method is that fluorine, chlorine and sulfur can be determined simultaneously. However it is a time consuming method. If only chlorine has to be analyzed in incinerator residues, the diluted nitric acid extraction provides results with acceptable accuracy and precision. If only sulfur has to be analyzed, CNS-analyzer seems to be appropriate. If fluorine concentration has to be determined, the oxidative high pressure digestion is the method of choice anyway, since diluted nitric acid extraction cannot dissolve fluorine species completely and the Wurzschmitt digestion is a more time consuming method than the oxidative high pressure digestion.

The precision, determined here on the basis of the mean confidence interval of a single digestion and a single subsequent concentration determination by ion chromatography, is about $30-35 \%$ for fluorine and better than $20 \%$ for chlorine and sulfur at a $95 \%$ confidence level. The accuracy of the fluorine, chlorine and sulfur concentrations determined by this method is better than $85 \%$.

Table VII. Analytical precision of the oxidative high pressure digestion combined with ion chromatography at a $95 \%$ confidence level.

\begin{tabular}{lcc}
\hline & $\begin{array}{c}\text { Bottom ash } \\
{[\%]}\end{array}$ & $\begin{array}{c}\text { APC residues } \\
{[\%]}\end{array}$ \\
\hline Fluorine & 27 & 35 \\
Chlorine & 19 & 15 \\
Sulfur & 9 & 18 \\
Sulfur determined with the & 12 & 8 \\
CNS-analyzer & & \\
\hline
\end{tabular}




\section{Original articles}

\section{References}

1. Barton, R. G.; Clark, W. D.; Seeker, W. R. Combust. Sci. and Tech. 1990, 74, 327-342.

2. Jakob, A.; Stucki, S.; Kuhn, P. Environ. Sci. and Techn. 1995, 29, 2429-2436.

3. Verhulst, D.; Buekens, A.; Spencer, P. J.; Eriksson, G. Environ. Sci. and Technol. 1996, 30, 50-56.

4. Belevi, H.; Moench, H. Environ. Sci. Technol. 2000, 34, 25012506.
5. Belevi, H.; Langmeier, M. Environ. Sci. Technol. 2000, 34, 2507-2512.

6. Belevi, H. Environmental engineering of municipal solid waste incineration; VDF-Verlag: Zurich, 1998.

7. Wurzschmitt, B. Microchimica Acta 1951, 36/37, 369.

8. Thiel, O. Ph.D. Thesis, Universität Hamburg, Hamburg, 1995.

9. Belevi, H.; Langmeier, M.; Mönch, H.; Turban, Y.; Müller, T.; Baccini, P. Müll und Abfall 1998, 82-94. 